\title{
A Novel Shortwave Infrared Proximal Sensing Approach to Quantify the Water Stability of Soil Aggregates
}

\author{
Azadeh Gholoubi ${ }^{1,2}$, Hojat Emami ${ }^{2}$, Scott B. Jones ${ }^{1}$ and Markus Tuller ${ }^{3}$ \\ ${ }^{1}$ Utah State University, Department of Plants, Soils and Climate, Logan, UT, USA \\ ${ }^{2}$ Department of Soil Science, Faculty of Agriculture, Ferdowsi University of Mashhad, Mashhad, Iran \\ ${ }^{3}$ The University of Arizona, Soil, Water and Environmental Science Department, Tucson, AZ, USA
}

Corresponsding author: Scott B. Jones - scott.jones@usu.edu

\section{Core Ideas:}

- A novel proximal sensing approach to determine soil aggregate stability is demonstrated.

- Change in pre- vs. post-wetted aggregate reflectance yields aggregate stability from surface structure alteration.

- Results were well-correlated with those of the high energy moisture characteristic (HEMC) method, which involves rapid and slow wetting of aggregates.

- The new method only employs rapid wetting of aggregates, saving time for sample processing and evaluation. 


\begin{abstract}
Soil structure and aggregate stability are critical soil properties affecting water infiltration, root growth, and resistance to soil and wind erosion. Changes in aggregate stability may be early indicators of soil degradation, pointing to low organic matter content, reduced biological activity or poor nutrient cycling. Hence, efficient and reliable aggregate stability measurement techniques are essential for detection, management, and remediation of degraded soil resources. Here we quantify soil aggregate stability by developing a novel proximal sensing technique based on shortwave infrared (SWIR) reflectance measurements. The novel approach is similar to the well-documented high energy moisture characteristic (HEMC) method, which yields a stability ratio (SR) derived from comparison of hydraulic and structural characteristics of slowly- and rapidly-wetted soil samples near-saturation. We rapidly wetted aggregated soil samples (i.e., high energy input) and hypothesized that an aggregate stability index can be derived from SWIR surface reflectance spectra due to differences in post-wetting surface roughness that is intimately linked to aggregate stability. To test this hypothesis, surface reflectance spectra from a wide range of structured soil textures under both slowly and rapidly-wetted samples, were measured with a SWIR spectroradiometer $(350-2500 \mathrm{~nm})$. The ratio between pre- and post-wetting spectra was determined and compared with the HEMC method's volume of drainable pore ratio (VDPR). We found a strong correlation $\left(\mathrm{R}^{2}=0.87\right)$ between the VDPR and the SWIR-derived reflectance index (RI) and also between the SR $\left(\mathrm{R}^{2}\right.$ $=0.90)$ and the RI for all soils. These results point to the feasibility and appeal of quantifying aggregate stability using the newly proposed and more time-efficient proximal sensing method.

Keywords: Soil aggregate stability, High energy moisture characteristic (HEMC), Shortwave infrared (SWIR) reflectance, Stability ratio (SR), Volume of drainable pore ratio (VDPR)
\end{abstract}

\title{
1. Introduction
}

A healthy soil structure is the basis for sustainable management of agricultural and natural ecosystems (Arthur et al., 2014; Dexter, 2004; Naveed et al., 2014). It affects many physicochemical and biological soil processes such as microbial activity (Six et al., 2004), organic matter dynamics (Denef et al., 2002), seedling emergence and root development (De Freitas et al., 1996), aeration and gas transport, water and nutrient storage and transport (Logsdon et al., 2013; Mamedov, 2014) as well as wind and water erosion (Nimmo and Perkins, 2002; Park and Smucker, 2005). The stability of soil aggregates is an important indicator of soil health and functioning. Changes in aggregate stability (AS) that is affected by clay mineralogy, biota, soil organic carbon (SOC), sesquioxides, ionic bridging, and carbonates (Barthès et al., 2008; Bronick and Lal, 2005, Nabavinia et al., 2015) may be an early indicator of soil degradation, pointing to low SOC, reduced biological activity or poor nutrient cycling. Hence, an in-depth understanding of soil aggregation and breakdown dynamics is crucial for detection, management, and remediation of degraded soil resources.

Aggregate breakdown due to water involves a variety of physicochemical processes occurring at scales ranging from clay particle interactions to the macroscopic behavior of aggregates. Le Bissonnais (1996) has identified four major mechanisms that promote soil aggregate breakdown as a consequence of wetting.

When dry aggregates are rapidly wetted, water penetrates the entire outer aggregate surface, which results in softening of the surface layers and at the same time in a pressure increase of the entrapped air. When the pressure of the entrapped air exceeds the strength of the softened outer layers, the air escapes, breaking the aggregate into smaller fragments (Ghezzehei, 2012). This process is referred to as "slaking" (Panabokke and Quirk, 1957).

If soils contain an appreciable amount of active clay minerals (i.e., 2:1 clays such as smectite) significant changes in volume occur during hydration (i.e., osmotic swelling) and dehydration. Nonuniform drying (i.e., unbalanced shrinkage) causes internal stresses that eventually lead to cracking and subsequent aggregate breakup and microaggregate formation (Kheyrabi and Monnier, 1968; Six, 2004). Swelling of 
aggregated soil (such as freshly tilled soil) results in joining of adjacent aggregates as they begin to invade each other's space (Ghezzehei, 2012).

Physicochemical dispersion is affected by the electrolyte concentration (EC) of the soil solution (Agassi et al., 1985) and is one of the most effective processes of aggregate breakdown (Le Bissonnais, 1996). Dispersion is also facilitated and enhanced by osmotic swelling and slaking.

Finally, mechanical breakdown of aggregates due to raindrop impact usually occurs in combination with the mechanisms discussed above, given that the kinetic energy of drop impacts exceeds a certain threshold (Nearing and Bradford, 1987; Huang and Bradford, 1992). This process is specifically effective when the soil surface is wet, because the surface aggregates are softened. For a detailed discussion of mechanical aggregate breakdown readers are referred to Le Bissonnais (1996) and Ghezzehei (2012).

In the past, various techniques based on hydraulic properties, aggregate size distribution, and aggregate stability measurements have been employed to quantify soil structural stability (Amézketa, 1999; Bronick and Lal, 2005; Childs, 1940; Dexter, 2004). An inherent problem, even of standardized methods such as wet sieving, is poor repeatability (Amézketa, 1999). Furthermore, there is no coherent scheme for correlating aggregate stability indices obtained with different methods.

An interesting technique for quantification of aggregate stability is the high energy moisture characteristic (HEMC) method (Childs, 1940; Pierson and Mulla, 1989; Levy et al., 2003). It is based on a controlled wetting process and the assumption that hydration forces (i.e., osmotic swelling), dispersion, and compressed entrapped air (i.e., slaking) breakup aggregates. Two structured subsamples are wetted from the bottom, one in slow and the other in rapid mode (i.e., different energy input). Based on a comparison of the post-wetting pore size distributions (PSDs) of the slowly- $\left(P S D_{\text {slow }}\right)$ and rapidly-wetted $\left(P S D_{\text {rapid }}\right)$ subsamples, the structure and aggregate stability are quantified. The larger the difference between $P S D_{\text {slow }}$ and $P S D_{\text {rapid, }}$, the lower the aggregate stability (Logsdon et al., 2013; Mamedov et al., 2010). The HEMC technique has been evaluated in numerous studies (e.g. Levy and Miller, 1997; Levy and Mamedov, 2002; Mamedov et al., 2010; Mandal et al., 2008; Mulla, 1991; Norton et al., 2006; Pierson and Mulla, 1990) with the conclusion that this method is sufficiently sensitive to detect even small changes in aggregate and structural stability for a range of soils collected in humid as well as in arid regions (Mamedov et al., 2010).

Diffuse reflectance spectroscopy was introduced as a powerful means for soil property quantification decades ago (Williams and Norris, 2001; Viscarra Rossel et al., 2006; Wu et al., 2009; Nocita et al., 2015; Veum et al., 2015; Knadel et al., 2017). It relies on a focused projection of a spectrometer beam onto a sample of interest, where it is reflected, scattered and transmitted through the sample material. The back reflected, diffusely scattered light (some of which is absorbed by the sample) is then collected by the accessory and directed to the detector optics (Lindbergh, 2009). Spectrometers that operate within the Vis, NIR and shortwave infrared (SWIR; 400-2500 nm) range are applied for both laboratory and field measurements. Water reduces reflectance in the VIS, NIR, and SWIR domains (Baumgardner et al., 1985; Liu et al., 2003) and therefore impacts the reflectance spectra of wet soil particles and agregates (Dalal and Henry, 1986; Hummel et al., 2001; Slaughter et al., 2001; Lobell, 2002; Weidong et al., 2002; Sadeghi et al., 2015, 2017). There also exists an intimate relationship between soil reflectance and particle size (Sadeghi, 2018 ; Bänninger et al., 2006; Bowers and Hanks, 1965; Hunt and Vincent, 1968; Klima, 2012; Myers et al., 2015; Qi et al., 2009). Fine-textured soils generally exhibit higher spectral reflectance than coarse-textured soils (Sadeghi et al., 2018; Baumgardner et al., 1985; Van der Meer, 1995; Ben-Dor et al., 1999; Bowers and Smith, 1972). Larger aggregates may cause micro-shadowing, which decreases surface reflectance (Cierniewski et al., 2002; Goldshleger et al., 2002).

Encouraged by the efficiency, cost-effectiveness, and high reproducibility of soil spectroscopic techniques, our objective in this study was to evaluate the feasibility of SWIR spectroscopy applied in conjunction with the HEMC method for quantification of aggregate stability. We hypothesized that aggregate breakdown during rapid wetting can be characterized and quantified via post-wetting SWIR surface reflectance. To test this hypothesis, surface reflectance spectra of rapidly-wetted structured soil samples, spanning a wide range 
of textures, were measured with a spectroradiometer $(350-2500 \mathrm{~nm})$. The ratio between pre-wetting drysurface and post-wetting dry-surface spectra was determined and compared with the HEMC volume of drainable pore (VDPR) and stability (SR) ratios.

\section{Materials and Methods}

Five thourougly characterized Arizona soils with varying textures, mineralogies, and organic matter (OM) contents (Table 1) were investigated. Particle size distributions were measured for each sample by means of the pipette/sieve method as described by Gee and Bauder (1986). Total organic matter content $(\mathrm{OM})$ was determined for subsamples by means of oxidation with sodium hypochlorite (NaOCl) (Jackson, 2005). The mineralogy was quantified with a PANalytical X'Pert Pro MPD Xray Diffractometer (XRD) (Malvern Panalytical Ltd., Royston, UK) and the RockJock software package (Eberl, 2003), which performs a whole-pattern modified Rietveld-type refinement. The electrical conductivity (EC) was measured in a 1:1 soil:water extract with a well calibrated standard benchtop EC meter. In addition, zeoponic aggregates comprised of zeolite (clinoptilolite) and rock phosphate (apatite) (Steinberg et al., 2000), which exhibit a rigid and stable structure, were used as a reference.

Table 1. Physicochemical and mineralogical properties of investigated soils. A dash indicates no detectable quantity was measured.

\begin{tabular}{|c|c|c|c|c|c|}
\hline Soil ID & AZ-7 & AZ-11 & AZ-13 & AZ-15 & AZ-18 \\
\hline Texture & Sandy Loam & Loam & Sandy Clay Loam & Silt Loam & Clay \\
\hline Clay $(\%)$ & 9.5 & 21.4 & 26.5 & 23 & 52.2 \\
\hline Silt (\%) & 32.0 & 40.1 & 15.4 & 73.4 & 18.7 \\
\hline Sand $(\%)$ & 58.5 & 38.5 & 58.1 & 3.6 & 29.1 \\
\hline $\mathrm{OM}(\%)$ & 1.1 & 1.7 & 2.8 & 3.4 & 4.0 \\
\hline $\mathrm{EC}\left(\mu \mathrm{S} \mathrm{cm} \mathrm{cm}^{-1}\right)$ & 830 & 495 & 836 & 3017 & 761 \\
\hline \multicolumn{6}{|c|}{ Mineralogy } \\
\hline Quartz (\%) & 29.5 & 30.4 & 17.5 & 20.3 & 13.3 \\
\hline Feldspar (\%) & 32.6 & 19.1 & 31.9 & 16.2 & 19.7 \\
\hline Amphibole (\%) & 1.0 & - & 0.7 & 1.8 & - \\
\hline 1:1 Clay - Kaolinite (\%) & 1.2 & 2 & 15.7 & 4.2 & 16.3 \\
\hline 2:1 Clay - Mica/Illite (\%) & 11.4 & 24.8 & 19.5 & 10.6 & 19.9 \\
\hline 2:1 Clay - Smectite (\%) & 20.6 & 18.7 & 5.4 & 10.7 & 18.0 \\
\hline 2:1:1 Clay $(\%)$ & 0.2 & - & 1.7 & 22.2 & 0.5 \\
\hline Muscovite/Biotite (\%) & 0.3 & - & 7.4 & 8.2 & 8.7 \\
\hline Halites $(\%)$ & - & 0.5 & - & - & 0.1 \\
\hline (Hydr)Oxides (\%) & - & 1.1 & 0.4 & - & 3.7 \\
\hline Carbonates (\%) & 3.3 & 3.3 & - & 5.8 & - \\
\hline
\end{tabular}




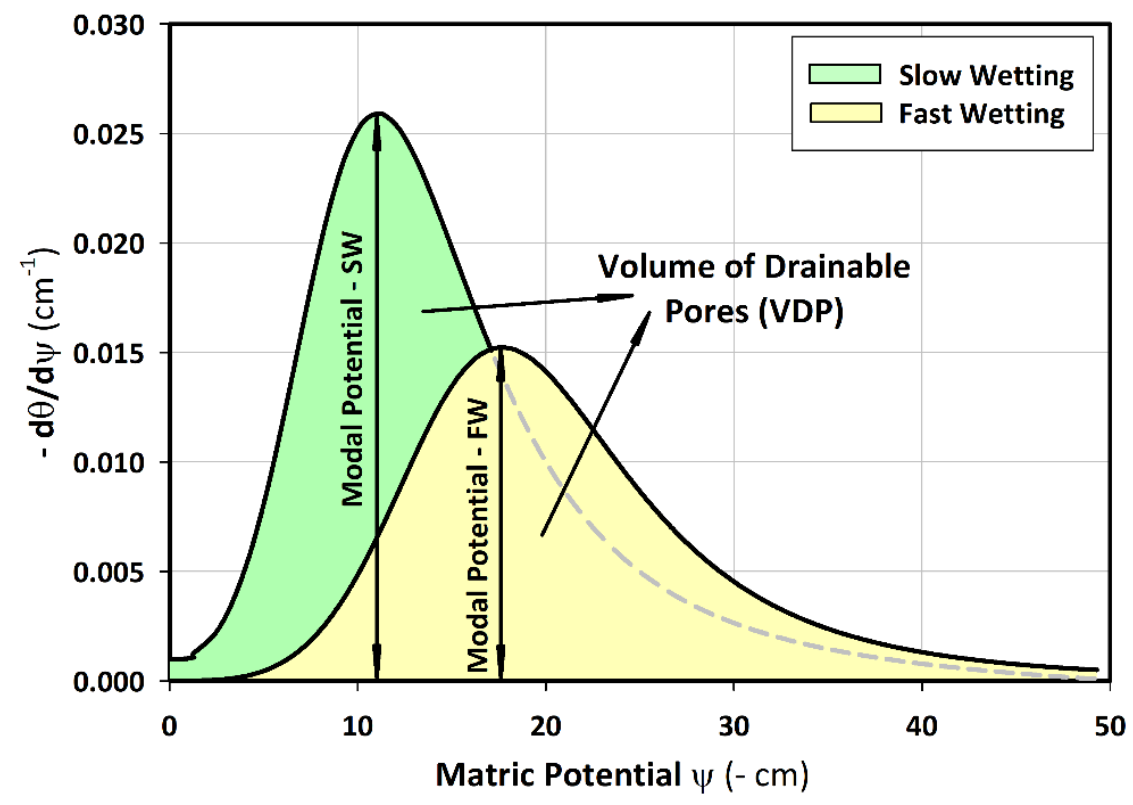

Figure 1. Schematic sketch of the specific water capacity curves for samples exposed to fast and slow wetting.

\subsection{High Energy Moisture Characteristic (HEMC) Method}

The HEMC method for estimation of aggregate stability was first proposed by Childs (1940) and later modified by Collis-George and Figueroa (1984), Pierson and Mulla (1989), and Levy and Mamedov (2002). For a detailed description of the experimental setup readers are referred to Levy and Mamedov (2002) and Mamedov et al. (2010). The basic idea behind the HEMC method is to first wet two similar macroaggregate $(0.5-1.0 \mathrm{~mm})$ subsamples from the bottom at two different rates (i.e., slow and fast), representing contrasting levels of energy input. After wetting, the water retention characteristics of both samples are measured with a hanging water column for the matric potential range from 0 to $-50 \mathrm{~cm} \mathrm{H}_{2} \mathrm{O}$. Then, a soil structure stability index (SI) is calculated based on the deviation between the two water retention curves. For each wetting rate, the SI is defined as the ratio of the volume of drainable pores (VDP) and the modal potential (MP). The MP corresponds to the matric potential $\psi\left(\mathrm{cm}^{-1}\right)$ at the peak of the specific water capacity curve $(\mathrm{d} \theta / \mathrm{d} \psi)$. The VDP is defined as the integral of the specific water capacity curve (i.e., area below the curve) (Fig. 1) (Collis-George and Figueroa, 1984). Soil structure and/or aggregate stability may be expressed via the indices of stability ratio (SR) and the VDP ratio (VDPR) (Levy and Miller, 1997; Levy et al., 2003).

\subsection{High Energy Moisture Characteristic (HEMC) Measurements and Analysis}

Twenty-five grams of aggregates $(0.5$ to $1.0 \mathrm{~mm})$ were placed into a glass Buchner funnel on top of a fritted glass disc to form a $\sim 7-\mathrm{mm}$ thick bed. Please note that the aggregate size range from 0.5 to $1.0 \mathrm{~mm}$ was chosen because smaller aggregates lack macropores, therefore do not release notable amounts of water within the applied matric potential range. With larger aggregates it is challenging to form a consistent bed on the fritted disc.

The fritted disc with a medium pore diameter of $12.5 \mu \mathrm{m}$ was saturated prior to aggregate placement. Tygon tubing was used to connect the funnel bottom to a syringe pump (Legacy Model 220, KD Scientific Inc., Holliston, MA, USA) to apply de-aired tap water. Two application rates, $100 \mathrm{~mm} \mathrm{hr}^{-1}$ representing fast 
wetting, and $2 \mathrm{~mm} \mathrm{~h}^{-1}$ for slow wetting were used. Water was applied until the aggregate samples were saturated (i.e., until a shiny surface was visible). Following sample saturation, the water retention characteristic was measured for the matric potential range from 0 to $-50 \mathrm{~cm} \mathrm{H}_{2} \mathrm{O}$ with a hanging water column connected to a calibrated burette. The measurements were performed by sequentially lowering the matric potential with the hanging water column in $2-\mathrm{cm} \mathrm{H}_{2} \mathrm{O}$ increments and documenting the volume of soil extracted water at each matric potential for gravimetric water content determination, while assuring that equilibrium was attained in-between subsequent measurements. The experimental setup is depicted in Fig. 2. All measurements were performed in duplicate for each soil and zeoponic, i.e., 2 subsamples were exposed to fast wetting and 2 subsamples to slow wetting.

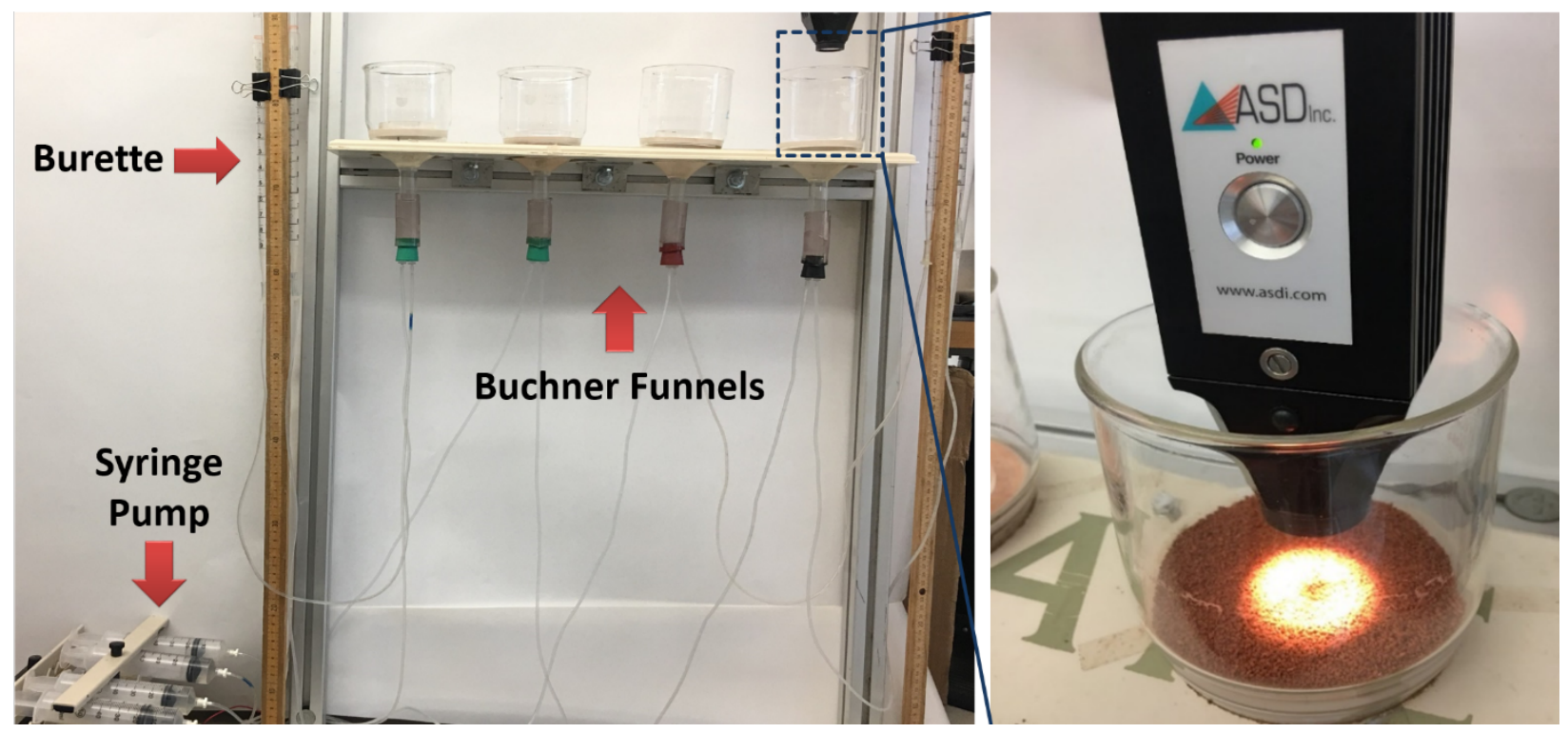

Figure 2. Experimental setup for high energy moisture characteristic (HEMC) and shortwave infrared (SWIR) reflectance measurements.

A modified van Genuchten (VG) (1980) model was then parameterized based on the measured $\theta-\psi$ data pairs via nonlinear regression (Pierson and Mulla, 1989; Levy et al., 2003; Mamedov et al., 2016):

$$
\theta=\theta_{r}+\left(\theta_{s}-\theta_{r}\right)\left[\frac{1}{1+(\alpha \psi)^{n}}\right]^{(1-1 / n)}+A \psi^{2}+B \psi+C
$$

where $\theta_{s}$ and $\theta_{r}$ are the pseudo saturated and residual water contents $\left(\mathrm{kg} \mathrm{kg}^{-1}\right)$, respectively (Pierson and Mulla, 1989), $\alpha\left(\mathrm{cm}^{-1}\right)$ and $\mathrm{n}(-)$ are shape parameters that determine the air-entry point and pore-size distribution, and $\mathrm{A}\left(\mathrm{cm}^{-2}\right), \mathrm{B}\left(\mathrm{cm}^{-1}\right)$, and $\mathrm{C}\left(\mathrm{kg} \mathrm{kg}^{-1}\right)$ are quadratic coefficients proposed by Pierson and Mulla (1989). A modified VG model with additional free parameters was applied because the original VG equation failed to yield accurate estimations of the VDP, while providing a precise estimate of modular potential (MP). Pierson and Mulla (1989) showed that the modified model accurately fits HEMC data.

From the obtained van Genuchten (1980) parameters the specific water capacity curve $(\mathrm{d} \theta / \mathrm{d} \psi)$ was calculated and analyzed to obtain the volume of drainable pores (VDP) and modal potential (MP) values:

$$
d \theta / d \psi=\left(\theta_{s}-\theta_{r}\right)\left[1+(\alpha \psi)^{n}\right]^{(1 / n-1)}(1 / \mathrm{n}-1)(\alpha \psi)^{n} n /\left\{\psi\left[1+(\alpha \psi)^{n}\right]\right\}+2 A \psi+B
$$

An example for the slowly wetted AZ-18 soil is shown in Fig. 3. 

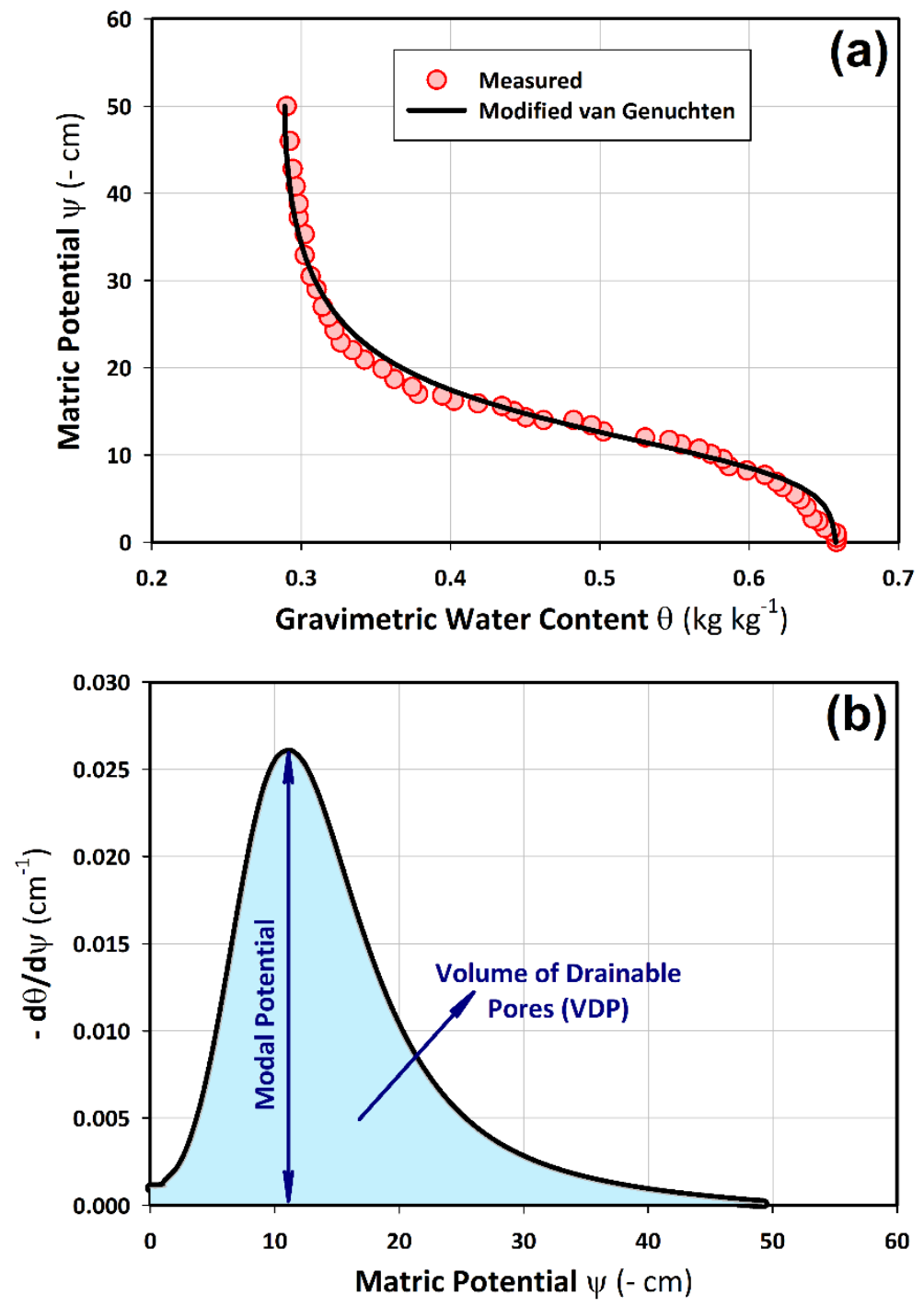

Figure 3. (a) Soil water characteristic for slowly wetted AZ-18 soil (measurements and modified VG model). (b) Specific water capacity curve for slowly wetted AZ-18 soil.

Finally, the structural index $\left(\mathrm{SI}, \mathrm{cm}^{-1}\right)$ and the stability ratio (SR) were calculated for each wetting rate as (Collis-George and Figueroa, 1984):

$$
\begin{gathered}
S I=\frac{V D P}{M P} \\
S R=\frac{S I_{\text {fast }}}{S I_{\text {slow }}}
\end{gathered}
$$

Another stability index (VDPR), the ratio of fast and slow VDP values was calculated as proposed by Levy and Miller (1997) and Levy and Mamedove (2002):

$$
V D P R=\frac{V D P_{\text {fast }}}{V D P_{\text {slow }}}
$$


The VDPR values range from 0 to 1 , where higher values indicate higher structural stability.

\subsection{Shortwave Infrared Reflectance Measurements and Analysis}

A LabSpec ${ }^{\circledR} 2500$ spectroradiometer (ASD Inc., Longmont, CO, USA) with a spectral range from 350 to $2500 \mathrm{~nm}$ was incorporated to measure spectral reflectance of the pre- and post-wetting dry surfaces of all rapidly wetted (i.e., $100 \mathrm{~mm} \mathrm{hr}^{-1}$ ) samples (Fig. 2). Note that after the SWC measurements with the hanging water column were obtained, the samples were oven-dried at $105^{\circ} \mathrm{C}$ prior to the second reflectance measurement. Prior to the SWIR measurements, the spectroradiometer was calibrated with a white Spectralon ${ }^{\circledR}$ Diffuse Reflectance Standard (Labsphere Inc., North Sutton, NH, USA). In addition, aggregate breakdown was visualized with a Dino-Lite ${ }^{\circledR}$ digital microscope (Dunwell Tech, Inc., Torrance, CA, USA). An example is shown in Figure 4 for fast and slow wetting of the AZ-13 aggregates.

Based on recent findings in Sadeghi et al. (2018), the aggregate reflectance at $2210 \mathrm{~nm}$ was selected for calculation of the reflectance index RI (-), which is simply the ratio of the $2210 \mathrm{~nm}$ reflectances of the ovendry pre- and post-wetted surfaces of the rapidly-wetted aggregates:

$$
R I=\frac{R_{2210-p r e}}{R_{2210-\text { post }}}
$$

The RI value ranges from 0 to 1 , with higher values indicating better structural stability.

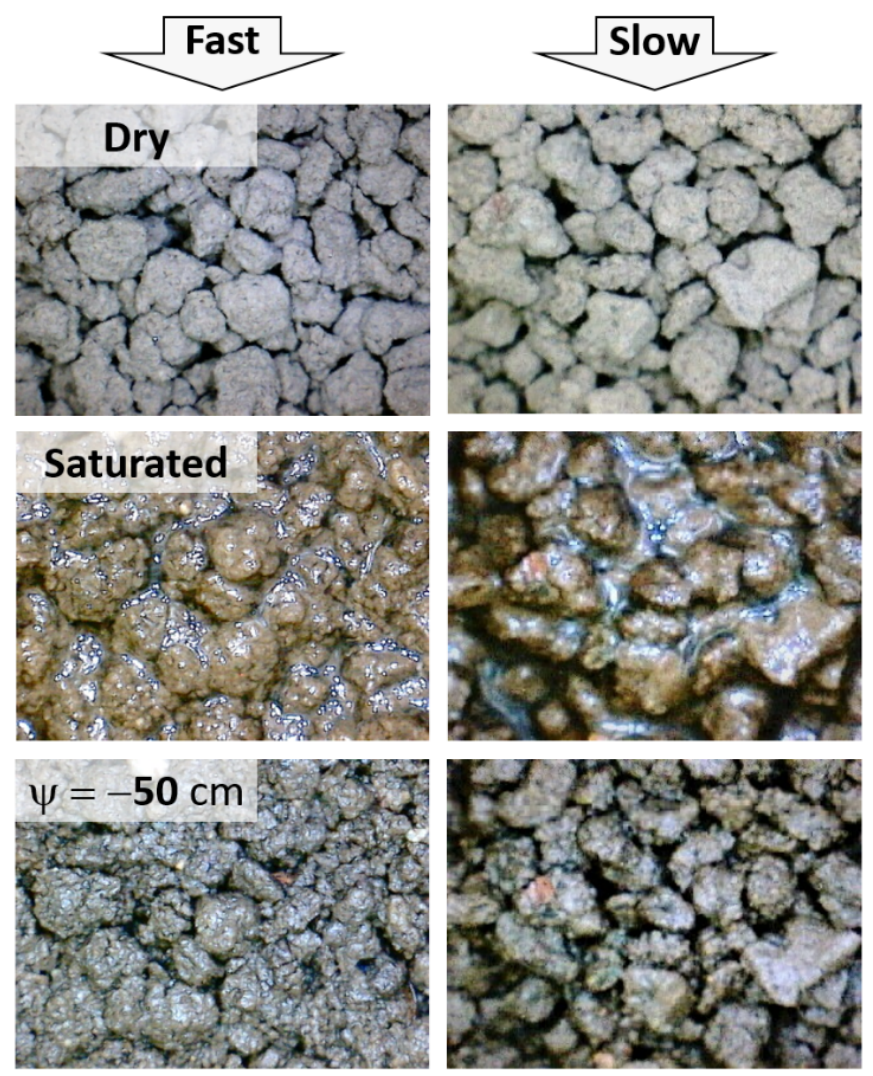

Figure 4. Visualization of sample wetting and draining to $-50 \mathrm{~cm}$ matric potential for the AZ-13 soil. 


\section{Results and Discussion}

Based on the HEMC theory, the difference between the water retention characteristic (WRC) curves measured for slowly and rapidly wetted aggregate samples is due to the change of the inter-aggregate pore size distribution (PSD) of the rapidly wetted sample that shifts toward a greater number of smaller pores (i.e., from macro to micro pores) due to aggregate breakdown (Pierson and Mulla, 1990, Levy and Mamedov, 2002; Logsdon et al., 2013). Figure 5 depicts examples for the WRC and specific water capacity curves for fast and slow wetting of the Zeoponic and AZ-18 aggregates. For stable aggregates, such as the Zeoponic, there is no observable change in the WRC and specific water capacity curves (Figs. 5a and 5b), hence, the structural indices (SIs) for slowly and rapidly wetted subsamples are the same and the stability ratio (SR) and the volume of drainable pore ratio (VDPR) are equal to 1.0 (Table 2). As expected, for unstable aggregates (e.g., AZ-18) there is a marked difference between the WRC and specific water capacity curves obtained for fast and slow wetting, respectively (Figs. 5c and 5d). It is evident that for unstable aggregates the SI for slowly wetted samples is higher than the SI obtained for rapid wetting (Table 2). These results are in agreement with previous studies (Levy and Mamedov, 2002; Levy and Miller, 1997; Mamedov et al., 2010; Pierson and Mulla, 1989).

While the VDPR and SR of Zeoponic are highest, the AZ-7 sandy loam, which is the least structured soil, exhibits the lowest VDPR and SR values of all investigated samples (Table 2). There is an observable decreasing trend of SRs with decreasing OM content. Among all of the investigated mineral soils, the AZ18 clay soil with the highest OM and clay content exhibited the highest SR and VDPR values (Tables 1 and 2 ) and the most stable aggregates relative to the zeoponic aggregates. Soil organic matter increases aggregate stability not only by cementing primary particles together, but it also decreases the wettability of aggregate surfaces due to hydrophobicity and adhesive humic acid films forming bridges between soil clay platelets, thereby reducing the magnitude of slaking (Tisdall and Oades, 1982; Chenu and Guerif, 1991; Chenu et al., 2000; Goldberg et al., 1988; Levy and Mamedov, 2002).
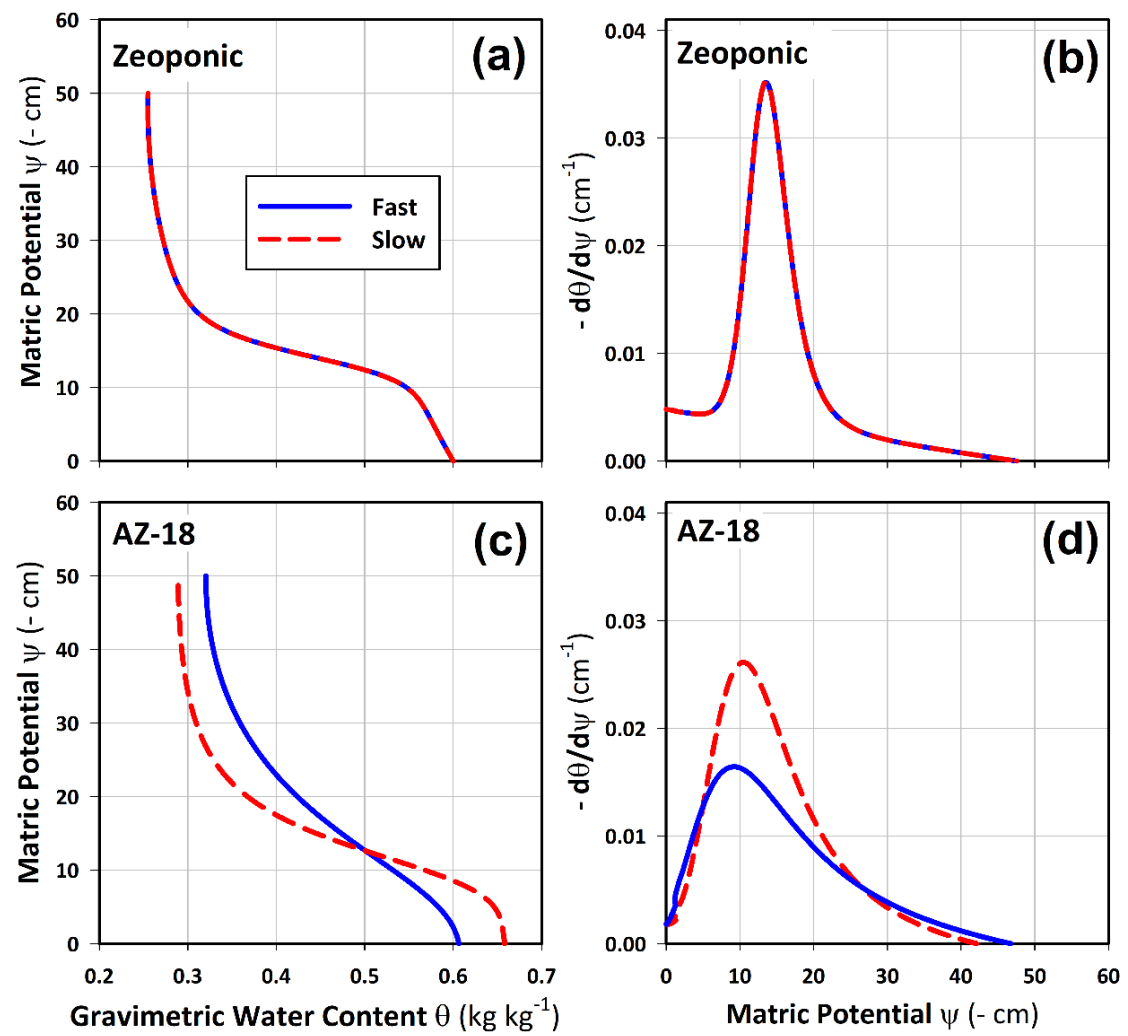

Figure 5. Examples for WRC and specific water capacity curves obtained with the HEMC method for the stable Zeoponic $(\mathrm{a}, \mathrm{b})$ and the unstable AZ-18 aggregates. 
The higher stability of the AZ-13 sandy clay loam aggregates in comparison with the AZ-15 silt loam aggregates can be attributed to its slightly higher clay content (i.e., 26.5\% for AZ-13 and 23.0\% for AZ-15) as well as to the clay mineralogy. The AZ-15 soil contains double the amount of smectite as the AZ-13 soil (Table 1). Smectite increases uneven osmotic swelling, which contributes to aggregate breakdown. Hence the VDPR and SR values for AZ-15 soil are lower then the values for AZ-13 soil, despite higher OM content (Table 2). Smectites easily disperse, have a large capacity for cation absorption, and exhibit extensive osmotic swelling during hydration (Vershin et al., 1966). Several studies have reported relationships between the SR and clay content (Levy and Mamedov, 2002; Levy and Miller, 1997; Levy et al., 2003; Norton et al., 2006; Ruiz-Vera and Wu, 2006), generally pointing to an increase of aggregate stability with increasing clay content.

Table 2. Mean values for the structural index (SI), volume of drainable pores (VDP), and modal potential (MP) as well as the derived VDPR, SR, and RI values for all investigated aggregate samples (note that all measurements were performed in dublicate).

\begin{tabular}{|c|c|c|c|c|c|c|c|c|}
\hline Soil name & Wetting rate & $\mathrm{OM}$ & VDP & $\mathrm{MP}(\mathrm{cm})$ & SI $\left(\mathrm{cm}^{-1}\right)$ & VDPR $^{*}$ & $\mathrm{SR}^{\dagger}$ & $\mathrm{RI}^{\ddagger}$ \\
\hline \multirow{4}{*}{ AZ-7 } & Fast-01 & 1.1 & 0.14 & 6.3 & 0.022 & \multirow{2}{*}{0.54} & \multirow{2}{*}{0.11} & \multirow{2}{*}{0.70} \\
\hline & Slow-01 & 1.1 & 0.26 & 1.3 & 0.200 & & & \\
\hline & Fast-01 & 1.1 & 0.19 & 8.3 & 0.023 & \multirow{2}{*}{0.61} & \multirow{2}{*}{0.24} & \multirow{2}{*}{0.76} \\
\hline & Slow01 & 1.1 & 0.31 & 3.3 & 0.094 & & & \\
\hline \multirow{4}{*}{ AZ-11 } & Fast-01 & 1.7 & 0.20 & 5.9 & 0.034 & \multirow{2}{*}{0.69} & \multirow{2}{*}{0.57} & \multirow{2}{*}{0.89} \\
\hline & Slow-01 & 1.7 & 0.29 & 4.8 & 0.060 & & & \\
\hline & Fast-02 & 1.7 & 0.21 & 8.2 & 0.026 & \multirow{2}{*}{0.64} & \multirow{2}{*}{0.53} & \multirow{2}{*}{0.84} \\
\hline & Slow-02 & 1.7 & 0.33 & 6.7 & 0.049 & & & \\
\hline \multirow{4}{*}{ AZ-13 } & Fast-01 & 2.8 & 0.29 & 11.3 & 0.026 & \multirow{2}{*}{0.85} & \multirow{2}{*}{0.79} & \multirow{2}{*}{0.95} \\
\hline & Slow-01 & 2.8 & 0.34 & 10.3 & 0.033 & & & \\
\hline & Fast-02 & 2.8 & 0.30 & 10.4 & 0.029 & \multirow{2}{*}{0.86} & \multirow{2}{*}{0.76} & \multirow{2}{*}{0.94} \\
\hline & Slow-02 & 2.8 & 0.35 & 9.3 & 0.038 & & & \\
\hline \multirow{4}{*}{ AZ-15 } & Fast-01 & 3.4 & 0.23 & 5.3 & 0.043 & \multirow{2}{*}{0.68} & \multirow{2}{*}{0.54} & \multirow{2}{*}{0.76} \\
\hline & Slow-01 & 3.4 & 0.34 & 4.3 & 0.079 & & & \\
\hline & Fast-02 & 3.4 & 0.23 & 5.6 & 0.041 & \multirow{2}{*}{0.74} & \multirow{2}{*}{0.59} & \multirow{2}{*}{0.84} \\
\hline & Slow-02 & 3.4 & 0.31 & 4.4 & 0.070 & & & \\
\hline \multirow{4}{*}{ AZ-18 } & Fast-01 & 4 & 0.36 & 9.3 & 0.039 & \multirow{2}{*}{0.88} & \multirow{2}{*}{0.98} & \multirow{2}{*}{0.97} \\
\hline & Slow-01 & 4 & 0.41 & 10.3 & 0.040 & & & \\
\hline & Fast-02 & 4 & 0.32 & 11.5 & 0.028 & 086 & 085 & 099 \\
\hline & Slow-02 & 4 & 0.37 & 11.3 & 0.033 & 0.80 & 0.03 & 0.0 \\
\hline & Fast-01 & - & 0.34 & 13.3 & 0.026 & 1 & 1 & 1 \\
\hline Zeononic & Slow-01 & - & 0.34 & 13.3 & 0.026 & 1 & 1 & 1 \\
\hline Leoponit & Fsat-02 & - & 0.31 & 13.2 & 0.023 & 1 & 1 & 1 \\
\hline & Slow-02 & - & 0.31 & 13.2 & 0.023 & 1 & 1 & 1 \\
\hline
\end{tabular}

${ }^{*}$ Volume of Drainable Pores Ratio (VDPR); ${ }^{\dagger}$ Stability Ratio (SR); ${ }^{\star}$ Reflectance Index (RI) 
The AZ-11 loam aggregates are more stable than the AZ-7 sandy loam aggregates. This may be a result of higher OM, metal oxide and clay contents of the AZ-11 soil (Table 1). Aggregates of soils with free metal oxides are commonly more stable than aggregates without oxides. Six et al. (2004) reported that iron and aluminum oxides act as binding agents, forming bridges between primary and secondray oxide-coated particles. The presence of metal oxides therefore may also lead to higher soil aggregate stability as exhibited in AZ-11 and AZ-18 (Tables 1 and 2).

Sample shortwave infrared (SWIR) spectra obtained for slowly and rapidly wetted AZ-13 aggregate samples during drying from saturation to $-50 \mathrm{~cm}$ matric potential are shown in Figure 6 . It is evident that for both, the slowly and rapidly wetted samples, the diffuse reflectance is lowest at saturation and increases with decreasing water content for all SWIR wavelengths. This is in agreement with other studies reporting an increase in reflectance with a decrease in moisture (Dalal and Henry, 1986; Hummel et al., 2001; Slaughter et al., 2001; Lobell and Asner, 2002; Weidong et al., 2002; Whiting et al., 2004; Mouazen et al., 2005; $\mathrm{Wu}$ et al., 2009). Characteristic water adsorption features (decrease in diffuse reflectance) are centered around SWIR wavelengths 1440, 1930, and $2200 \mathrm{~nm}$ (Knadel et al, 2014). These features are due to characteristics and overtones of the three major vibration frequencies of water, namely symmetric $\mathrm{OH}$ stretching, asymmetric $\mathrm{OH}$ stretching, and $\mathrm{OH}$ bending (Hunt, 1977). The spectrally active forms of water in the soil include free water, adsorbed water, and hydration water (Ben-Dor, 2002). Hydration water is incorporated into the mineral lattice with two strong $\mathrm{OH}$ absorption features near 1440 and $1930 \mathrm{~nm}$, and is related to the mineralogy of the sample (Knadel et al., 2014). Adsorbed water exists on the surfaces of clay minerals in the form of a thin layer (Tuller et al., 1999), and typically has an absorption band around $2200 \mathrm{~nm}$. An increase in clay content results in a more pronounced adsorption feature at $2200 \mathrm{~nm}$ (Workman and Weyer, 2007; Wu et al., 2009). The SWIR wavelength of $2210 \mathrm{~nm}$ was used to determine the reflectance index RI. (Sadeghi et al., 2018)
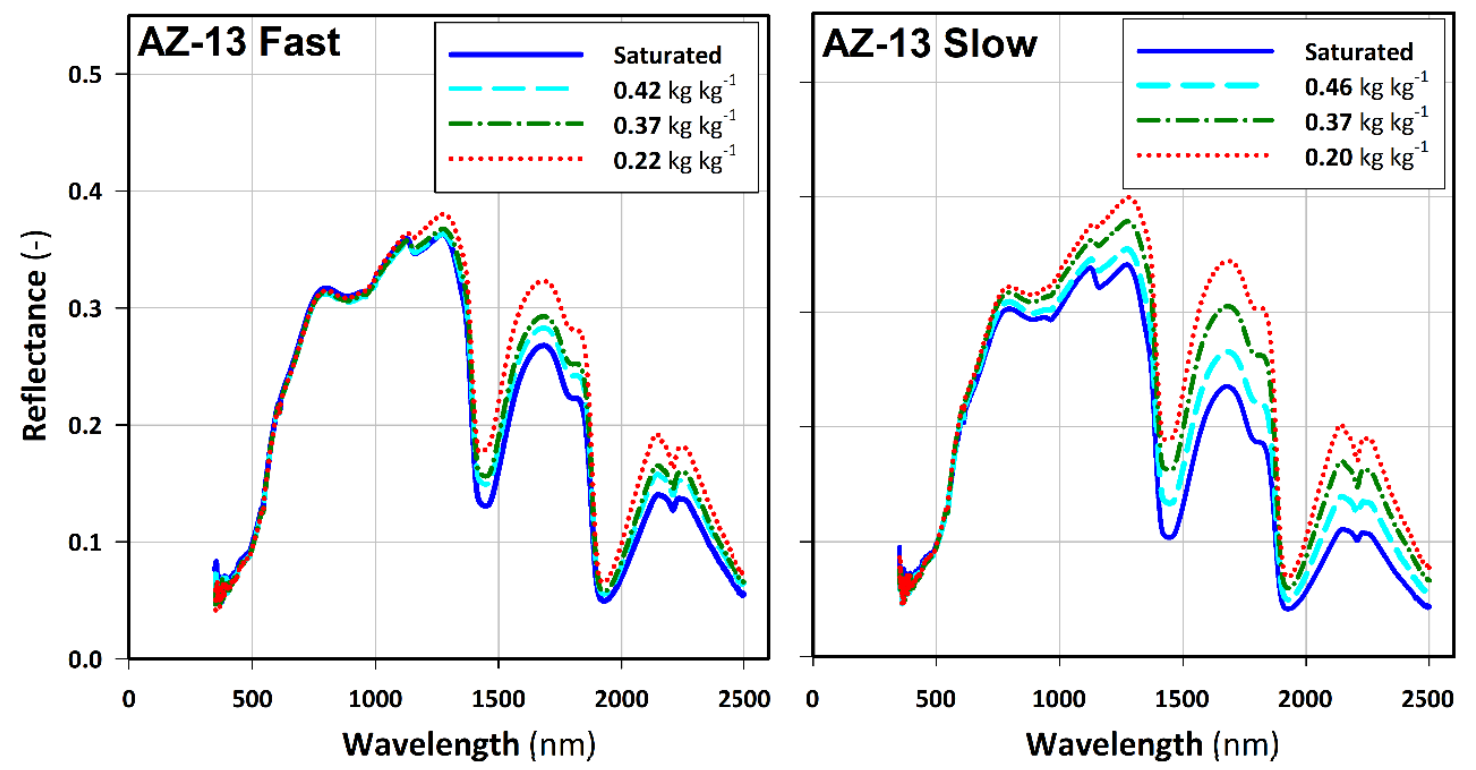

Figure 6. Effects of soil water content on SWIR reflectance spectra for rapidly and slowly wetted AZ-13 aggregates.

As demonstrated in Sadeghi et al. (2018), there is a strong correlation between aggregate size and diffuse reflectance at $2210 \mathrm{~nm}$ under oven-dry conditions. The reflectance increases with decreasing aggregate size. We capitalized on this finding and measured the SWIR reflectance spectra of the pre- and post-wetting oven-dry surfaces of rapidly wetted aggregate samples (Fig. 7) and used the $2210 \mathrm{~nm}$ relectance values to calculate the reflectance index (RI). With a range from 0 to 1 , higher values of RI indicate better structural 
aggregate stability. Significant aggregate breakup during rapid wetting leads to smaller aggregates and therefore to a lower RI value (Table 2). The mechanisms for aggregate breakup discussed above are within the context of the HEMC results presented here. Figure 7 illustrates the deviation between the average prewetting (initial) and post-wetting (final) reflectance spectra of two replicates of each samples, which increases following the order Zeoponic, AZ-18, AZ-13, AZ-11, AZ-15, and AZ-7.
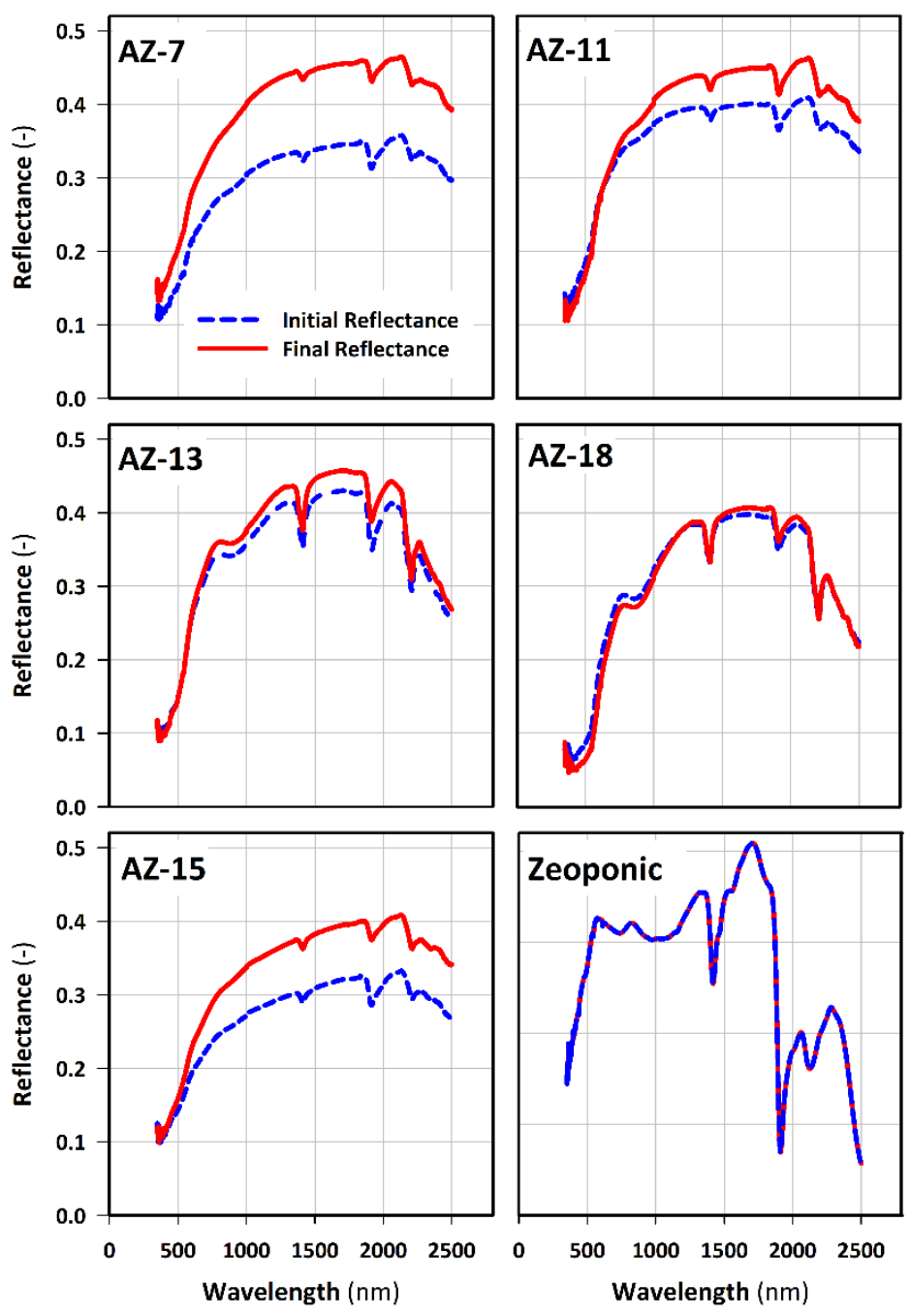

a

Figure 7. Measured reflectance spectra of oven-dry samples pre- and post-rapid wetting

To demonstrate the utility of the proposed SWIR proximal sensing approach for quantifying the water stability of soil aggregates, we correlated the SWIR reflectance-derived RIs with the HEMC-derived SRs and VDPRs in Figure 8. The results indicate strong linear correlations between SR and RI $\left(\mathrm{R}^{2}=0.8951\right)$ and VDPR and RI $\left(\mathrm{R}^{2}=0.8661\right)$, which highlights the value and quality of the novel SWIR imaging approach for aggregate stability assessment. 

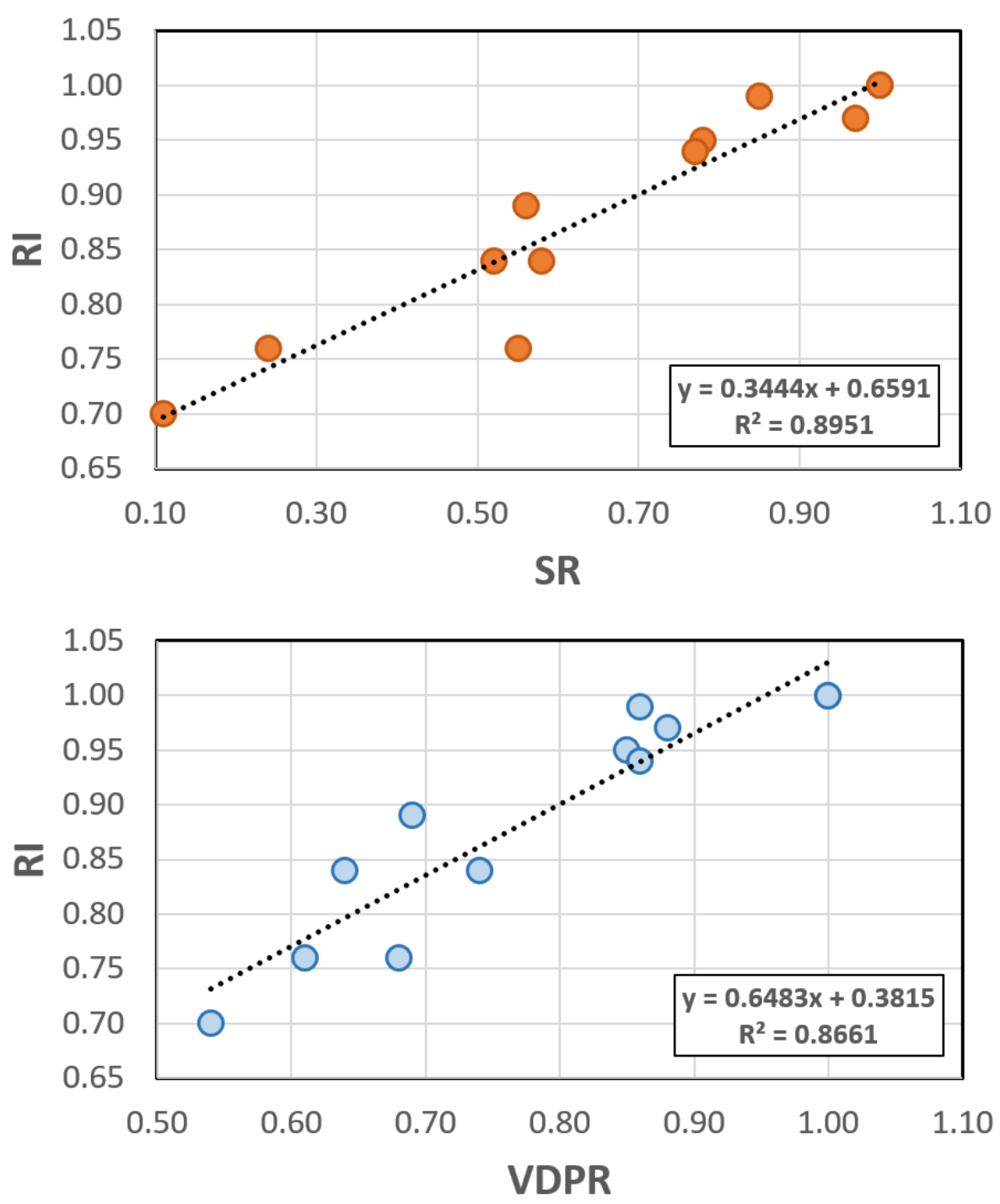

Figure 8. Linear correlations between Stability ratio and Reflectance index (a) and Volume of drainable Pores ratio and Reflectance index (b). The dotted lines represent the regression lines.

\section{Summary and Conclusions}

A novel shortwave infrared (SWIR) proximal sensing approach for quantification of the water stability of soil aggregates was introduced as an alternative to standard aggregate stability measurement techniques such as the more labor-intensive high energy moisture characteristic (HEMC) method. Results from five mineral soil aggregate samples spanning a wide range of textures demonstrated the benefits and utility of SWIR imaging. The SWIR-derived reflectance index is strongly correlated to the HEMC-derived SR and VDPR. Our recommendation is that the newly derived and tested RI provides an excellent alternative approach for determination of an aggregate water stability index. Advantages of the new approach are twofold; 1) it is much less labor intensive, only requiring two reflectance measurements on oven-dry aggregate samples before and after rapid wetting, and 2) spectroscopic techniques are highly reproducible and commonly do not require multiple replicates for representative results. We conclude that the proposed method provides new powerful means for measurement of the water stability of aggregates. Nevertheless, additional measurements for a broader range of textures and OM contents and comparison to other standard methods such as wet sieving are needed to qualify the new SWIR imaging approach as a standard method. 


\section{Acknowledgements:}

We acknowledge funding from the National Science Foundation (NSF) via grants no. 1521469 and 1521164 awarded to Utah State University and to the University of Arizona. Additional support was provided by the Utah Agricultural Experiment Station (UTAO1189), Utah State University, Logan, Utah 84322-4810, approved as UAES journal paper no. 9094.

\section{References}

Agassi, M., J. Morin, andI. Shainberg. 1985. Effect of raindrop impact energy and water salinity on infiltration rates of sodic soils. Soil Sci. Soc. of Am. J. 49: 186- 190.

Amézketa, E. 1999. Soil Aggregate Stability : A Review. J. Sustain. Agric. 14: 83-151. doi:10.1300/J064v14n02

Arthur, E., P. Schjønning, P. Moldrup, F. Razzaghi, , M. Tullerand L.W. De Jonge. 2014. Soil structure and microbial activity dynamics in 20-month field-incubated organic-amended soils. Eur. J. Soil Sci. 65(2): 218-230. doi:10.1111/ejss.12121

Bänninger, D., P. Lehmann, and H. Flühler. 2006. Modelling the effect of particle size, shape and orientation of light transfer through porous media. Eur. J. Soil Sci. 57(6): 906-915. doi:10.1111/j.1365-2389.2005.00787.x

Barthès, B.G., E. Kouakoua, M.C. Larré-Larrouy, T.M. Razafimbelo, E.F. de Luca, A. Azontonde, et al.2008. Texture and sesquioxide effects on water-stable aggregates and organic matter in some tropical soils. Geoderma 143(1-2): 14-25. doi:10.1016/j.geoderma.2007.10.003

Baumgardner, M.F., L.F. Silva L.L. Biehl. and E.R. Stoner. 1985. Reflectance properties of soils. Adv. Agron. 38: 1-44. doi:10.1016/S0065-2113(08)60672-0

Ben-Dor, E. 2002. Quantitative remote sensing of soil properties. Adv. Agron. 75:173-243.

Bowers, S. A., and R.J. Hanks. 1965. Reflection of radiant energy from soils. Soil Sci. 100(2): 130-138. doi:10.1097/00010694-196508000-00009

Bronick, C.J., and R.. Lal. 2005. Soil structure and management: A review. Geoderma 124(1-2): 3-22. doi:10.1016/j.geoderma.2004.03.005

Chenu, C., and J. Guerif. 1991. Mechanical Strength of Clay-Minerals As Influenced By an Adsorbed Polysaccharide. Soil Sci. Soc. Am. J. 55(4): 1076-1080.

Chenu, C., Y. Le Bissonnais, and D. Arrouays. 2000. Organic Matter Influence on Clay Wettability and Soil Aggregate Stability. Soil Sci. Soc. Am. J. 64(4): 1479-1486.

doi:10.2136/sssaj2000.6441479x

Childs, E.C., 1940. The Use of Soil Moisture Characteristics in Soil Studies. J. Soil Sci.

Cierniewski, J., M. Verbrugghe, andA. Marlewski. 2002. Effects of farming works on soil surface bidirectional reflectance measurements and modelling. Int. J. Remote Sens. 23(6): 1075-1094. doi:10.1080/01431160110071897

Collis-George, N., and B.S. Figueroa. 1984. The use of high energy moisture characteristic to assess soil stability. Aust. J. Soil Res. 22(3): 349-356. doi:10.1071/SR9840349

Dalal, R.C., and R.J. Henry. 1986. Simultaneous determination of moisture, organic carbon, and total nitrogen by near infrared reflectance spectrophotometry. Soil Sci. Soc. Am. J. 50(1): 120-123. doi:10.2136/sssaj1986.03615995005000010023x 
De Freitas, V.P., V. Abrantes, and P. Crausse. 1996. Moisture Migration in Building Walls - Analysis of the Interface Phenomena. Build. Environ. 31(2): 99-108. doi:10.1016/0360-1323(95)00027-5

Denef, K., J. Six, R. Merckx, and K. Paustian. 2002. Short-term effects of biological and physical forces on aggregate formation in soils with different clay mineralogy. Plant Soil 246: 185-200. doi:10.1023/a:1020668013524

Dexter, A. R. 2004. Soil physical quality Part I. Theory, effects of soil texture, density, and organic mailer, and effects on root growth. Geoderma 120: 201-214.

doi:10.1016/j.geodermaa.2003.09.005.

Eberl, D.D. 2003. User Guide to RockJock - A Program for Determining Quantitative Mineralogy from X-Ray Diffraction Data. In: Open-File Report OF 03-78, 56 p.

Gee, G.W., and J.W. Bauder. 1986. Particle-size analysis. In: A. Klute, editor, Methods of soil analysis. Part 1. 2nd ed. Agron. Monogr. 9. ASA and SSSA, Madison, WI. p. 383-411.

Ghezzehei, T.A., 2012. Soil structure. Handbook of soil science, 2, pp.1-17.

Goldshleger, N., E. Ben-Dor, Y. Benyamini, D. Blumberg, and M. Agassi.2002. Spectral properties and hydraulic conductance of soil crusts formed by raindrop impact. Int. J. Remote Sens. 23(19): 3909-3920. doi:10.1080/01431160110115942

Huang, C., and J.M. Bradford. 1992. Applications of a Laser Scanner to Quantify Soil Microtopography. Soil Sci. Soc. Am. J. 56: 14-21. doi:10.2136/sssaj1992.03615995005600010002x

Hummel, J.W., K.A. Sudduth, andS.E. Hollinger. 2001. Soil moisture and organic matter prediction of surface and subsurface soils using an NIR soil sensor. Comput. Electron. Agric. 32(2): 149-165. doi:10.1016/S0168-1699(01)00163-6

Hunt, G.R., and R.K. Vincent. 1968. The Behavior of Spectral Features in the Infrared Emission from Particulate Surfaces of Various Grain Sizes. J. Geophys. Res. 73(18): 6039-6046. doi:10.1029/JB073i018p06039

Jackson, M.L. 2005. Soil chemical analysis: Advanced course. 2nd ed. UW Madison Libraries Parallel Press, Madison, WI. p. 37.

Kheyrabi, D. and G. Monnier. 1968. tude expe'rimentale de l'influence de la composition granulome'trique des terres sur la stabilite' structurale. Ann. Agric 19: 129_152.

Klima, R. 2012. Theory of reflectance and emittance spectroscopy. Meteorit. Planet. Sci. 47(8): 14031404. doi:10.1111/j.1945-5100.2012.01391.x

Knadel, M., F. Deng, A. Alinejadian, L.W. de Jonge, P. Moldrup, and M.H. Greve. 2014. The Effects of Moisture Conditions-From Wet to Hyper dry-On Visible Near-Infrared Spectra of Danish Reference Soils. Soil. Sci. Soc. Am. J. 78:422-433.

Knadel, M., R. Gislum, C. Hermansen, Y. Peng, P. Moldrup, L.W. de Jonge, and M.H. Greve. 2017. Comparing predictive ability of laser-induced breakdown spectroscopy to visible near-infrared spectroscopy for soil property determination. Biosyst. Eng. 156: 157-172. doi:10.1016/j.biosystemseng.2017.01.007

Le Bissonnais, Y. 2016. Aggregate stability and assessment of crustability and erodibility: 1. Theory and methodology. European Journal of Soil Science, 47: 425-437.: Reflections by Y. Le Bissonnais. Eur. J. Soil Sci. doi:10.1111/ejss.2_12311 
Levy, G., and A.I. Mamedov. 2002. High-Energy-Moisture-Characteristic Aggregate Stability as a Predictor for Seal Formation. Soil Sci.Soc.Am.J. 66: 1603-1609. doi:10.2136/sssaj2002.1603

Levy, G., and W. Miller.1997. Aggregate stabilities of some Southeastern US soils. Soil Sci. Soc. Am. J. 61:1176-1182.

Levy, G.J., A.I. Mamedov, and D. Goldstein.2003. Sodicity and water quality effects on slaking of aggregates from semi-arid soils. Soil Sci. 168(8): 552-562. doi:10.1097/01.ss.0000085050.25696.52

Liu, W., F. Baret,X. Gu, B. Zhang, Q. Tong, and L. Zheng. 2003. Evaluation of methods for soil surface moisture estimation from reflectance data. Int. J. Remote Sens. 24(10): 2069-2083. doi:10.1080/01431160210163155

Lindbergh, T. 2009. Quantitative diffuse reflectance spectroscopy: myocardial oxygen transport from vessel to mitochondria (Doctoral dissertation, Linköping University Electronic Press).

Lobell, D.B. and A, G.P. 2002. Moisture effects on soil reflectance. Soil Sci. Soc. Am. J. 66(3): 722-727.

Logsdon, S., M. Berli, and R. Horn. 2013. Quantifying and modeling soil structure dynamics. doi:10.2134/advagricsystmodel3.c1

Mamedov, A.I. 2014. Soil water retention and structure stability as affected by water quality. Eurasian J. Soil Sci. 3(2): 89. doi:10.18393/ejss.24378

Mamedov, A.I., B. Bar-yosef, I. Levkovich, R. Rosenberg, A. Silber, P. Fine, and G.J. Levy.2016. Amending Soil With Sludge, Manure, Humic Acid, Orthophosphate and Phytic Acid : Effects on Infiltration, Runoff and Sediment 1639(2): 1629-1639.

Mamedov, A.I., L.E. Wagner, C. Huang, L.D. Norton, and G.J. Levy. 2010. Polyacrylamide Effects on Aggregate and Structure Stability of Soils with Different Clay Mineralogy. Soil Sci. Soc. Am. J. 74(5): 1720-1732. doi:10.2136/sssaj2009.0279

Mandal, U.K., A.K. Bhardwaj, D.N. Warrington, D. Goldstein, A. Bar Tal, andG.J. Levy. 2008. Changes in soil hydraulic conductivity, runoff, and soil loss due to irrigation with different types of salinesodic water. Geoderma 144(3):509-516. doi:10.1016/j.geoderma.2008.01.005

Mouazen, A.M., J. De Baerdemaeker, andH. Ramon.2005. Towards development of on-line soil moisture content sensor using a fibre-type NIR spectrophotometer. Soil Tillage Res. 80(1): 171-183. doi:10.1016/j. still.2004.03.022

Mulla, D.J. 1991. Estimation of Soil Properties and Wheat Yields on Complex Eroded Hills Using Geostatistics and Thematic Mapper Images Estimation of Soil Properties and Wheat Yields on Complex Eroded Hills Using Geostatistics and Thematic Mapper Images. 191(9): 181-191. doi:10.1016/0034-4257(91)90080-P

Myers, T.L., C.S. Brauer, Y.-F. Su, T.A. Blake, R.G. Tonkyn, A.B. Ertel, T.J. Johnson, andR.L. Richardson. 2015. Quantitative reflectance spectra of solid powders as a function of particle size. Appl. Opt. 54(15): 4863-4875. doi:10.1364/AO.54.004863.

Nabavinia, F., H. Emami, A. Astaraee, and A. Lakzian. 2015. Effect of tannery wastes and biochar on soil chemical and physicochemical properties and growth traits of radish. International Agrophysics, 29(3):333-339. 
Naveed, M., E. Arthur, L.W.De Jonge, M. Tuller, and P. Moldrup. 2014. Pore structure of natural and regenerated soil aggregates: An x-ray computed tomography analysis. Soil Sci. Soc. Am. J. 78(2): 377-386. doi:10.2136/sssaj2013.06.0216.

Nearing, M.A., and J.M. Bradford. 1987. Relationships Between Waterdrop Properties and Forces of Impact1. Soil Sci. Soc. Am. J. 51(2): 425-430. doi:10.2136/sssaj1987.03615995005100020031x

Nimmo, J.R., and K.S. Perkins. 2002. 2.6 Aggregate stability and size distribution. Methods of soil analysis: part, 4:317-328.

Nocita, M., A. Stevens, B. van Wesemael, M. Aitkenhead, M. Bachmann, B. Barthès, et al. 2015. Soil Spectroscopy: An Alternative to Wet Chemistry for Soil Monitoring, in: Advances in Agronomy. 132:139-159. doi:10.1016/bs.agron.2015.02.002

Norton, L.D., A.I. Mamedov, G.J. Levy, andC. Huang. 2006. Soil aggregate stability as affected by longterm tillage and clay mineralogy. Adv. Geoecology 38: 422-429.

Pierson, F.B., and D.J. Mulla. 1990. Aggregate stability in the Palouse region of Washington. Effect of landscape position. Soil Sci. Soc. Am. J. 54: 1407-1412. doi:10.2136/sssaj 1990.03615995005400050033x

Panabokke, C.R., and J.P. Quirk.1957. Effect of initial water content on stability of soil aggregates in water. Soil Science, 83(3):185-196.

Park, E.J. and A.J. Smucker. 2005. Erosive strengths of concentric regions within soil macroaggregates. Soil Science Society of America Journal, 69(6):1912-1921.

Pierson, F.B., and D.J. Mulla. 1989. An Improved Method for Measuring Aggregate Stability of a Weakly Aggregated Loessial Soil. Soil Sci. Soc. Am. J. 53(6):1825-1831. doi:10.2136/sssaj1989.03615995005300060057x

Qi, Y., J.L. Darilek, B. Huang, Y. Zhao, W. Sun, and Z. Gu. 2009. Evaluating soil quality indices in an agricultural region of Jiangsu Province, China. Geoderma 149: 325-334. doi:10.1016/j.geoderma.2008.12.015

Ruiz-Vera, V.M., and L. Wu. 2006. Influence of sodicity, clay mineralogy, prewetting rate, and their interaction on aggregate stability. Soil Science Society of America Journal, 70(6):1825-1833.

Sadeghi, M., E. Babaeian, M. Tuller, and S. B. Jones. 2018. Effects of particle size on soil reflectance explained by an analytical radiative transfer model. Remote Sens. Environ. 210: 375-386.

Sadeghi, M., E. Babaeian, M. Tuller, and S. B. Jones. 2017. The optical trapezoid model: A novel approach to remote sensing of soil moisture applied to Sentinel-2 and Landsat- 8 observations. Remote Sens. Environ. 198: 52-68. doi:10.1016/j.rse.2017.05.041

Sadeghi, M., S.B. Jones, and W.D. Philpot. 2015. A linear physically-based model for remote sensing of soil moisture using short wave infrared bands. Remote Sens. Environ. 164: 66-76. doi:10.1016/j.rse.2015.04.007

Shukla, M.K., R. Lal, and M. Ebinger. 2004. Soil Quality Indicators for the North Appalachian Experimentalwatersheds in Coshocton Ohio. Soil Sci. 169(3): 195-205. doi:10.1097/01.ss.0000122523.03492.79

Six, J., H. Bossuyt, S. Degryze, andK. Denef. 2004. A history of research on the link between (micro)aggregates, soil biota, and soil organic matter dynamics. Soil Tillage Res. 79(1):7-31. doi:10.1016/j.still.2004.03.008 
Slaughter, D.C., M.G. Pelletier, andS.K. Upadhyaya. 2001. Sensing soil moisture using NIR spectroscopy. Appl. Eng. Agric. 17(2): 241-247.

Steinberg, S.L., D.W. Ming, K.E. Henderson, C. Carrier, J.E. Gruener, D.J. Barta andD.L. Henninger. 2000. Wheat response to differences in water and nutritional status between zeoponic and hydroponic growth systems. Agron. J. 92(2): 353-360. doi:10.1007/s100870050044

Tisdall, J., and J. Oades.1982. Organic matter and water stable aggregates in soils. J. soil Sci. 33(2): 141163. doi:10.1111/j.1365-2389.1982.tb01755.x

Tuller, M., D. Or, andL.M. Dudley. 1999. Adsorption and capillary condensation in porous media - liquid retention and interfacial configurations in angular pores. Water Resour. Res. 35 (7): 1949-1964.

Van der Meer, F. 1995. Spectral reflectance of carbonate mineral mixtures and bidirectional reflectance theory: Quantitative analysis techniques for application in remote sensing. Remote Sens. Rev. 13: 67-94. doi:10.1080/02757259509532297

Vershin, P.V., M.K. Melnikova, B.N. Michurin, B.S. MoshkovN.P. Poyasov, and A.F. Chudnovskii. 1966. Fundamental of Agrophysics. Israel program for scientific translations, Herusalem, Israel.

Veum, K.S., K.A. Sudduth, R.J. Kremer, andN.R. Kitchen. 2015. Estimating a Soil Quality Index with VNIR Reflectance Spectroscopy. Soil Sci. Soc. Am. J. 79(2): 637-649. doi:10.2136/sssaj2014.09.0390

Viscarra Rossel, R. A., D.J.J. Walvoort, A. B. McBratney, L.J. Janik, andJ.O. Skjemstad. 2006. Visible, near infrared, mid infrared or combined diffuse reflectance spectroscopy for simultaneous assessment of various soil properties. Geoderma. 131(1): 59-75.

doi:10.1016/j.geoderma.2005.03.007

Weidong, L., F. Baret, G. Xingfa, T. Qingxi, Z. Lanfen, andZ. Bing. 2002. Relating soil surface moisture to reflectance. Remote Sens. Environ. 81(2): 238-246. doi:10.1016/S0034-4257(01)00347-9

Whiting, M.L., L. Li, and S.L. Ustin. 2004. Predicting water content using Gaussian model on soil spectra. Remote Sens. Environ. 89(4): 535-552. doi:10.1016/j.rse.2003.11.009

Williams, P., and K. Norris. 2001. Near Infrared Technology in the Agricultural and Food Industries, Near-infrared technology in the agricultural and food industries, second edition.

Workman, J., and L. Weyer. 2007. Practical Guide to Interpretive Near-Infrared Spectroscopy.

Wu, C.Y., A.R. Jacobson, M. Laba, and P.C. Baveye. 2009. Accounting for surface roughness effects in the near-infrared reflectance sensing of soils. Geoderma 152(1): 171-180.

doi:10.1016/j.geoderma.2009.06.002 